\title{
ANNOUNCEMENT
}

\section{Transfer of the Calvin H. Stevens Coral Collection to the University of California Museum of Paleontology, Berkeley, California}

\author{
Calvin H. Stevens ${ }^{1}$ and Erica C. Clites ${ }^{2}$ \\ ${ }^{1}$ Department of Geology, San Jose State University, San Jose, California 95125 USA 〈calvin.stevens@ sjsu.edu〉 \\ ${ }^{2}$ University of California Museum of Paleontology, Berkeley, California 94720 USA〈eclites@ berkeley.edu〉
}

Corals collected by Dr. Calvin H. Stevens and previously curated in the Geology Department, San Jose State University, San Jose, California, have been transferred to the University of California Museum of Paleontology, Berkeley, California. The collection consists of more than 850 hand samples and thin sections accumulated over a span of $\sim 50$ years. The majority of specimens are colonial forms from the Permian of western USA, but the collection also includes specimens ranging in age from the Ordovician to the Triassic from around the world. San Jose State University catalog numbers (SJS) originally assigned have been recataloged into the online University of California Museum of Paleontology (UCMP) database (http://ucmpdb.berkeley.edu/). Catalogued localities are UCMP IP657-IP1277 and these can be searched (http://ucmpdb.berkeley.edu/advanced.html). The SJS numbers can be entered in the "Other Catalog Number" field to access metadata associated with this collection. The thin sections are divided into the following categories: General, Oversized, Figured specimens, and Type specimens. Separate thin section collections from specific geographic areas (i.e., Warm Spring Canyon, California) are also present. The collection includes holotypes, paratypes, figured specimens, and representatives of previously identified species. An accompanying sample catalog on file in UCMP includes lists of figured specimens, holotypes, paratypes, types with associated rock samples, and references, in addition to unpublished maps. Some holotypes, and paratypes in the C.H. Stevens collection have been deposited in the National Museum of Natural History, Smithsonian Institution, Washington, D.C., rather than the UCMP.

Accepted 14 December 2015 